\title{
A SURVEY OF THE GENETICAL BASIS OF HETEROSIS IN A VARIETY OF DIALLEL CROSSES
}

\author{
J. L. JINKS \\ Agricultural Research Council Unit of Biometrical Genetics, \\ University of Birminghom
}

\section{INTRODUCTION}

Received 22.ix.54

THERE are at present two principal hypotheses concerning the genetical basis of heterosis. The one holds that heterosis is caused by bringing together in the hybrid the dominant favourable genes of both parents (Jones, I9I7). The second theory holds that heterozygosity per se is responsible for heterosis (East and Hayes, I9I2 ; East and Jones, I919; Shull, 1948). More recently East (1936) sought to explain heterosis in terms of the complementary action of alleles at the same locus, a phenomenon which has variously been described as "superdominance " (Fisher, Immer and Tedin, r932) and " overdominance" (Hull, r945).

These two theories approach one another to the limit where it is impossible, from the practical point of view, to distinguish between alleles and closely linked genes. They hold important differences, however, for the practical breeder, since they propose two different methods of attaining maximum improvement. If the first theory is correct, it should be possible to gain maximum improvement by accumulating the maximum number of dominant favourable genes in the homozygous condition. The ease vith which this can be achieved will be dependent on the linkage relations of the genes concerned and the degree of success will be dependent on the extent to which linkages of alleles in opposition are recombined. On the other hand, if the second theory is correct, maximum productiveness will follow only upon maximum heterozygosity, i.e. the heterosis is completely unfixable in the homozygous state.

Recently a method of analysing diallel crosses based on the methods described by Mather (I 949) has been developed (Jinks and Hayman, I953; Jinks, I 954a, I954b; Hayman, I954) which allows one to discriminate between heterosis arising from interaction between alleles at one locus and between genes at different loci. The present paper sets out the results obtained on applying this method of analysis to a wide range of diallel crosses and related crossing programmes reported in the literature.

\section{METHOD}

In the present analysis we estimate from genetic parameters $D$, $\mathrm{H}_{1}, \mathrm{H}_{2}$ and $\mathrm{F}$ (see Jinks loc. cit. and Hayman loc cit.). Dominance is measured as $\frac{\mathrm{H}_{1}}{\mathrm{D}}$ which are weighted sums of $\mathrm{h}^{2}$ and $\mathrm{d}^{2}$ respectively ( $d$ and $h$ being the additive and dominance components of variation), 
the weighting being in favour of genes with both alleles represented equally in the parents. $\frac{\mathrm{H}_{2}}{4 \mathrm{H}_{1}}$ provides an estimate of the mean value of $\mathrm{uv}$, i.e. $\overline{\mathrm{uv}}$ (with a maximum value of $\frac{1}{4}$ when $\mathrm{u}=\mathrm{v}=\frac{1}{2}$ ) and shows whether or not positive and negative alleles are present in equal proportions. This again is weighted, but this time in favour of genes showing the greater value of dominance, giving no information about genes showing no dominance. $F$ is an indication of the relative frequencies of dominant and recessive alleles, being positive if there is an excess of dominants.

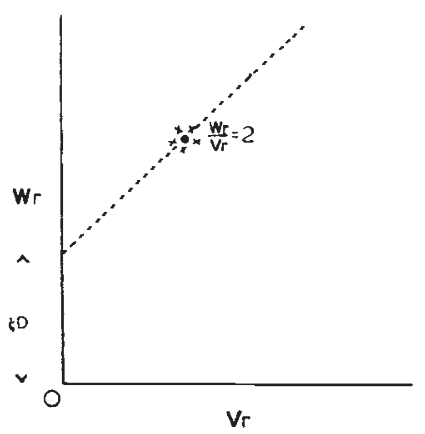

1a. No dominance

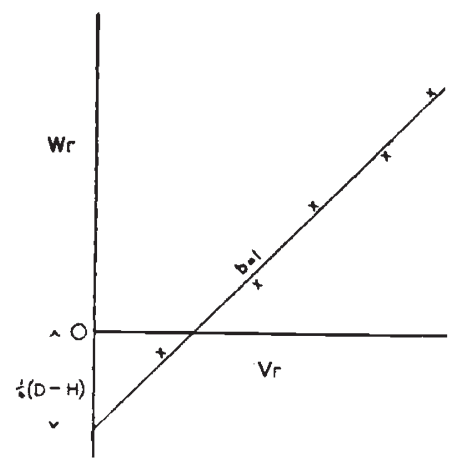

1c. Overdominance

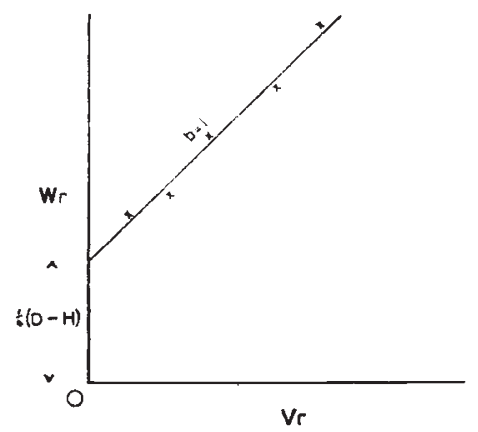

1b. Incomplete dominance

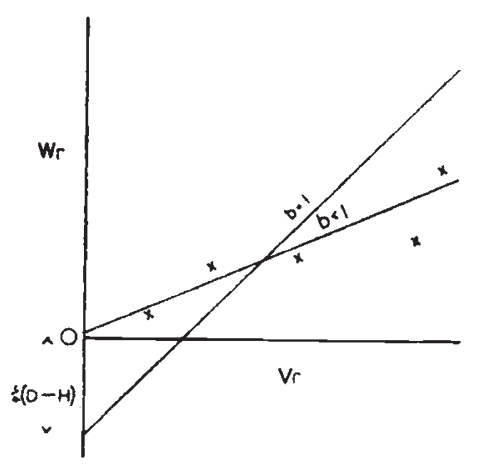

1d. Spurious overdominance arising from presence of non-allelic interaction along with complete dominance.

Fig. 1.-The regression of $\mathrm{Wr}$ on $\mathrm{Vr}$ for various degrees of dominance $(\mathrm{s} a-\mathrm{I} c)$. Id shows how spurious overdominance may arise in these analyses as a result of non-allelic interaction.

Our test of the significance of the degree of dominance and its partitioning into true dominance and spurious dominance arising from non-allelic interaction is achieved by the regression of $\mathrm{Wr}$ on $\mathrm{Vr}$ (the covariance and variance of arrays respectively). In the absence of dominance there is no regression, all array variances and covariances being estimates of a single point where $\frac{\mathrm{Wr}}{\mathrm{Vr}}=2$ (fig. Ia). Dominance uncomplicated by non-allelic interaction gives a regression 
of unit slope which cuts the $\mathrm{Wr}$ axis on the positive side for incomplete dominance, at zero for complete dominance and on the negative side for overdominance (fig. $\mathrm{I} b$ and $\mathrm{I} c$ ). The deviation of this point of intersection of the regression line and the $\mathrm{Wr}$ axis from the origin is equal to $\frac{1}{4} \mathrm{D}-\frac{1}{4} \mathrm{H}_{1}$, and hence its standard error can be calculated. The presence of non-allelic interaction leads to a deviation from unit slope giving a slope less than unity (fig. Ic), which should allow one to detect its presence irrespective of the degree of dominance.

\section{EXAMPLES}

\section{(i) Maize}

The most extensive of the sets of diallel crosses available in maize are those of Kinman and Sprague (1945). These consist of a ro by Io $F_{1}$ diallel and the means of $F_{2}$ families raised from these $F_{1} s$. These data have previously been analysed by Hull (1946) using the method of constant parent regression. This revealed significant overdominance in the $\mathrm{F}_{1} \mathrm{~s}$ but complete absence of dominance in the $\mathrm{F}_{2} \mathrm{~s}$.

The re-analyses of these observations are given in columns $I$ and 2 of table I.

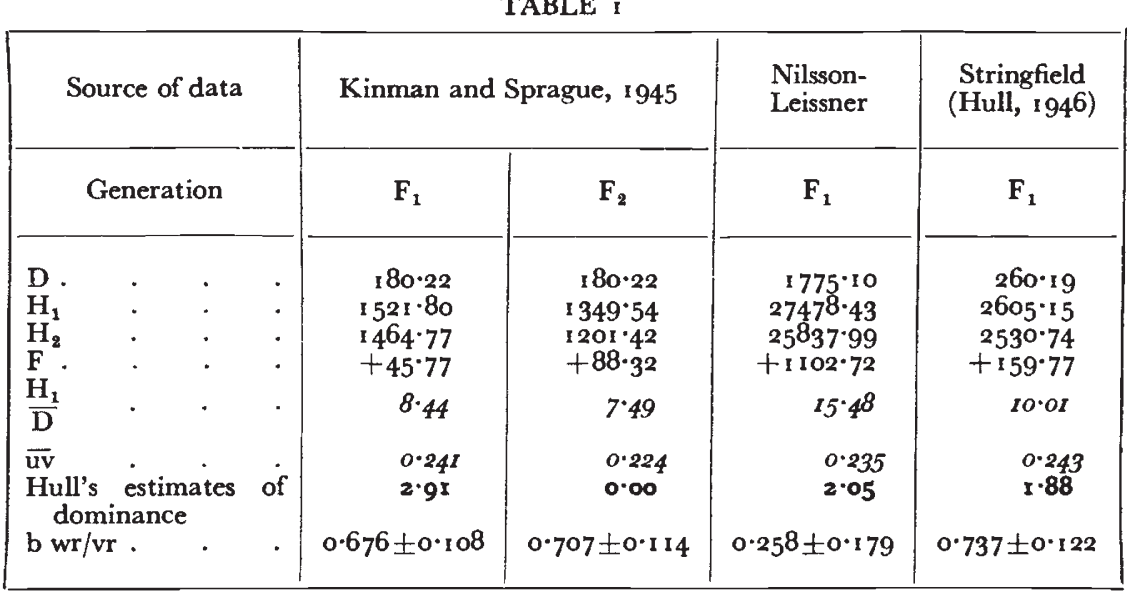

In our present analyses $F_{1}$ and $F_{2}$ give high and consistent overdominance. The $\mathrm{F}_{1}$ regression of $\mathrm{Wr}$ on $\mathrm{Vr}$, the test for non-allelic interaction, is also significant, being less than $\mathrm{r}(\mathrm{b}=0.676 \pm 0 . \mathrm{ro8})$. The main sources of interaction can be traced by omitting the progeny of the parental lines one at a time and in various combinations until an improvement of the regression slope is observed.

In this way it has been possible to show that in Kinman and Sprague's data parent $\mathrm{B}_{2}$ and, to a lesser extent, $\mathrm{Hy}$ and $\mathrm{OhO}_{7}$ are responsible for the bulk of the non-allelic interaction. Thus omitting the progeny of $\mathrm{B}_{2}$ gives a regression of $0.754 \pm 0 \cdot 098$, while removing $\mathrm{B}_{2}$ and $\mathrm{Hy}$ or $\mathrm{B}_{2}$ and $\mathrm{OhO}_{7}$ gives regressions of $0.788 \pm 0.075$ and $0.808 \pm 0.086$ respectively. The latter is doubtfully no longer significantly different from a slope of $\mathrm{I}(\mathrm{P}=0 \cdot 05-0 \cdot 02)$. 
While omitting the progeny of these three lines removes all the significant deviations arising from non-allelic interaction, it does not, of course, exhaust the sources of interaction present in the original parents. Each of the lines picked out must be interacting with at least one other parental line, that has been retained, to have been detected at all.

If we apply the scaling test (Mather, 1949) we find that we have not removed all the significant non-allelic interaction by omitting the progenies of parents $\mathrm{B}_{2}, \mathrm{Hy}$ and $\mathrm{OhO}_{7}$. For the purposes of the scaling test the diallel crosses are separated into the individual crosses, each consisting of the two parents, an $F_{1}$ mean and an $F_{2}$ family mean. The expectation in terms of $\mathrm{d}, \mathrm{h}$ and the mid parent $\mathrm{M}$ are :-

$$
\begin{aligned}
& \overline{\mathrm{P}}_{1}=\mathrm{M}+\Sigma \mathrm{d}(\Sigma \mathrm{d} \text { is the balance of genes in opposition }) \\
& \overline{\mathrm{P}}_{2}=\mathrm{M}-\Sigma \mathrm{d} \\
& \overline{\mathrm{F}}_{1}=\mathrm{M}+\Sigma \mathrm{h} \\
& \overline{\mathrm{F}}_{2}=\mathrm{M}+\Sigma \frac{1}{2} \mathrm{~h}
\end{aligned}
$$

\begin{tabular}{|c|c|c|c|c|c|c|c|c|c|}
\hline & $\mathrm{Cl}_{14}$ & $\mathbf{R}_{46}$ & $3^{8 \cdot I I I}$ & $\mathrm{~B}_{2}$ & $\mathrm{WF}_{9}$ & $\mathrm{OhO}_{7}$ & $\mathrm{OhO}_{4}$ & $w_{7}$ & $\mathrm{~K}_{159}$ \\
\hline $\begin{array}{l}\mathrm{Hy} \\
\mathrm{Cl}_{4} 4 \\
\mathrm{R}_{4} 6 \\
3^{8} \cdot 1 \mathrm{I} \\
\mathrm{B}_{2} \\
\mathrm{WF}_{9} \\
\mathrm{OhO}_{7} \\
\mathrm{OhO}_{4} \\
\mathrm{WV}_{7}\end{array}$ & - & + & $\begin{array}{l}+ \\
+ \\
-\end{array}$ & $\begin{array}{l}\bar{z} \\
\overline{-}\end{array}$ & $\begin{array}{l}\bar{z} \\
\overline{+}\end{array}$ & $\begin{array}{l}- \\
- \\
- \\
\pm\end{array}$ & $\begin{array}{l}\overline{-} \\
\overline{-} \\
\overline{+} \\
-\end{array}$ & $\begin{array}{l}= \\
= \\
- \\
\pm \\
= \\
=\end{array}$ & $\begin{array}{l}- \\
z \\
z \\
= \\
z \\
+\end{array}$ \\
\hline
\end{tabular}

so that for each cross of the diallel table $\frac{1}{4} \overline{\mathrm{P}}_{1}+\frac{1}{4} \overline{\mathrm{P}}_{2}+\frac{1}{2} \overline{\mathrm{F}}_{1}-\overline{\mathrm{F}}_{2}=0$ in the absence of non-allelic interaction. One can, therefore, test for

FIG. 2

non-additivity of gene action by testing this equality. For greater accuracy, the modified scaling test proposed by Cavalli (1953) was used. The test consists of estimating by weighted least squares the three parameters $\Sigma \mathrm{d}, \Sigma \mathrm{h}$ and $\mathrm{M}$, taking as weights the reciprocals of the squared standard errors of each generation mean. These parameters can then be tested for consistency over generations, in this particular case, by a $\chi^{2}$ for one degree of freedom.

Applying this test of additivity of gene action to Kinman and Sprague's data we find that there is significant deviation from simple additivity in Io of the 45 crosses. These results are summarised in fig. 2, where + indicates non-additivity and - additivity on the present scale.

On this basis the parental lines can be divided into a number of 
groups the members of which are similar in showing non-allelic interaction in crosses involving members of a second group (fig. 2).

These results tie up as well as can be expected with the $F_{1}$ regression test for non-allelic interactions. The latter not only picked out B2 as the main source of interaction, a result that is completely borne out by the scaling test, but actually accounted for 6 out of the ro $F_{1}$ combinations showing non-allelic interaction.

We can now make estimates of the degree of dominance in one section of the data that contains no crosses exhibiting non-allelic interactions. This section comprises the four arrays whose common parents are $\mathrm{Hy}, \mathrm{Cli}_{4}, \mathrm{R}_{4} 6$ and $3^{8 \cdot \mathrm{I}} \mathrm{I}$, and whose non-common parents are $\mathrm{B}_{2}, \mathrm{WF}_{9}, \mathrm{OhO}_{7}, \mathrm{OhO}_{4}, \mathrm{WV}_{7}$ and $\mathrm{K}_{5} 5$ for all the arrays. Using a modification of the diallel analysis described in detail under the section on flax (page 233) we can obtain two estimates of dominance $\frac{\mathrm{H}_{1}}{\mathrm{D}}=2.43$ and $2.7 \mathrm{I}$, which represent a fall in dominance of $7 \mathrm{I}$ per cent. and 68 per cent. respectively from the value found for the inclusive analysis (table I). Our experience with another crop, Nicotiana rustica (Jinks, I $954 b$ ), is very similar. There the high spurious overdominance was not merely reduced but disappeared after omitting all crosses from the diallel analysis where non-allelic interaction had been demonstrated leaving only complete dominance, i.e. $\frac{\mathrm{H}_{1}}{\mathrm{D}}=\mathrm{I}$.

The alternative method of attempting to remove interaction, i.e. changing the scale, has proved unsuccessful. No one transformation has been found which will remove non-additivity in the crosses where it is present and maintain the status quo where it was formerly absent. For example, a log transformation removes all significant nonadditivity in crosses where it was observed on the linear scale but a number of crosses where it was not previously observed, e.g. $\mathrm{B}_{2} \times \mathrm{K}_{\mathrm{I}} 59$, $\mathrm{WV}_{7} \times 3^{8 \cdot \mathrm{I}}$ and $\mathrm{R}_{4} 6 \times \mathrm{OhO}_{4}$ now show significant non-additivity. Furthermore, the $F_{1}$ regression of $\mathrm{Wr}$ on $\mathrm{Vr}$ on the log scale differs significantly from unit slope $(b=0.694 \pm 0.07 \mathrm{I})$, again indicating non-allelic interaction. On the new scale the highest incidence of interaction is in arrays $\mathrm{OhO}_{4}$. It can be seen, therefore, that there is no prospect of obtaining an estimate of dominance unbiased by non-allelic interaction by this method.

The mean yield of $F_{1}$ families showing non-allelic interaction is 90.27 compared with $77 \cdot 30$ for the non-interacting $F_{1}$ s, the mean of the parents giving rise to these $\mathrm{F}_{1} \mathrm{~s}$ being 29.49 and $27.9 \mathrm{I}$ respectively. On the average therefore, the $F_{1}$ families showing non-allelic interaction yield 13 bu/acre more than those showing no such interaction. It would thus appear that whereas general combining ability may be due to the operation of dominance in the $F_{1}$ families, non-allelic interaction must be implicated in the special combining ability which leads to the outstanding $F_{1}$ families. 
It is impossible to assess from the data available how far the general combining ability is the result of heterozygosity per se. For one thing we can never be certain that we have removed all non-allelic interaction from data simply because we can no longer detect any significant deviations due to its action. It is, however, worth noting that an $\frac{\mathrm{H}_{1}}{\mathrm{D}}$ greater than I obtained in these analyses, even after removing all non-allelic interaction, is not automatically ascribable solely to overdominance. Not only can linkage between genes in opposition give rise to spurious overdominance but it can also arise from the mere non-random association of genes in the parental lines. This is the general case of Jones' ( $19 \mathrm{I} 7$ ) theory of heterosis. Thus if we have two genes A-a and B-b appearing only in the opposition associations, i.e. $\mathrm{Ab}$ and $\mathrm{aB}$ in the parental lines, the dominance ratio $\frac{\mathrm{H}_{1}}{\mathrm{D}}$ no longer estimates $\frac{\Sigma \mathrm{h}_{\mathrm{a}}{ }^{2}+\mathrm{h}_{\mathrm{b}}{ }^{2}}{\Sigma \mathrm{d}_{\mathrm{a}}{ }^{2}+\mathrm{d}_{\mathrm{b}}{ }^{2}}$ but $\frac{\Sigma\left(\mathrm{h}_{\mathrm{a}}+\mathrm{h}_{\mathrm{b}}\right)^{2} \text {, }}{\Sigma\left(\mathrm{d}_{\mathrm{a}}-\mathrm{d}_{\mathrm{b}}\right)^{2}}$ which is, of course, an overestimate of the true degree of dominance.

TABLE 2

\begin{tabular}{|c|c|c|c|c|c|}
\hline & & & & Complete data & $\begin{array}{c}\text { Omitting progenies } \\
\text { of line } 1\end{array}$ \\
\hline D. & . & . & . & $3^{6 \cdot 982}$ & $4^{1} \cdot 316$ \\
\hline $\mathrm{H}_{1}$ & . & . & . & $1527 \cdot 111$ & $1292 \cdot 211$ \\
\hline $\mathrm{H}_{2}$ & . & . & . & $143^{2} \cdot 062$ & $1259^{\circ} 703$ \\
\hline$F^{2}$. & . & . & . & -0.676 & $+45.55^{8}$ \\
\hline$\frac{\mathrm{H}_{1}}{\mathrm{D}}$ & - & . & . & $4 I \cdot 293$ & $3 x \cdot 276$ \\
\hline$\overline{\mathrm{uv}}$. & . & . & • & 0.234 & 0.244 \\
\hline b. & . & . & • & $0.396 \pm 0.34^{8}$ & $0.705 \pm 0.160$ \\
\hline
\end{tabular}

The analysis of two further sets of maize data (Nilsson-Leissner, 1927) and Stringfield (Hull, I946) agree as far as they go with the situation found in the data of Kinman and Sprague. In the absence of further generations a detailed analysis of non-allelic interaction is not justified.

One further maize diallel has been analysed which, although only a 5 by 5 set of crosses, contains information regarding the incidence of non-allelic interaction and the past history of the inbred lines. This is contained in a paper by Rameshwar Singh (1953) and relates to his $\mathrm{R} \times \mathrm{R}$ crosses, the character under consideration once more being yield.

The relationship between the 5 parental lines can best be expressed if we number them I to 5 such that line I has no immediate past history in common with $2,3,4$ or 5 , whereas 2,3 and 4 have one grandparent in common while 3,4 and 5 have one parent in common. The analysis of the complete data is set out in table 2. 
Reference to the $\mathrm{Wr}, \mathrm{Vr}$ graph shows that the point for line I deviates most from the expected slope of I. On omitting the progenies of this line from the analysis, there is a 25 per cent. drop in the degree of overdominance and a marked improvement in the $\mathrm{Wr}, \mathrm{Vr}$ regression, although there is evidence that the non-allelic interaction has still not been wholly removed. The point for line 2 now deviates most from the expected slope, but the diallel is unfortunately too small to pursue the removal of non-allelic interaction any further. Even so a general picture of the situation is suggested, namely that in this set of crosses the intensity of non-allelic interaction can be related to the degree of relationship between the parental lines. Furthermore, our central theme is borne out by the fact that the omission of crosses showing non-allelic interaction leads to a fall in what can only now be described as spurious overdominance.

If we list the arrays in the order of the intensity of interaction displayed by these analyses, we find a marked positive correlation with the mean yield of their members (table 3 ).

TABLE 3

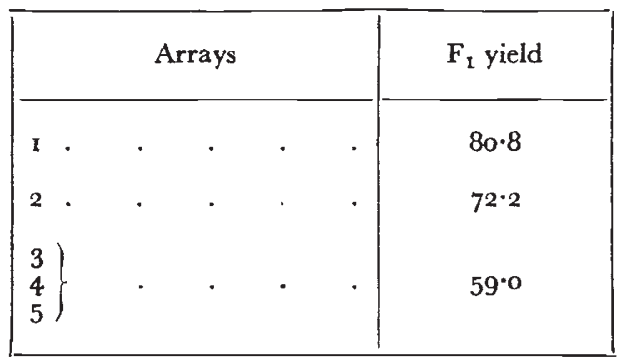

As in the data of Kinman and Sprague we find that the ability to produce outstanding $F_{1}$ yields, i.e. specific as opposed to general combining ability, are associated with the presence of non-allelic interaction.

\section{(ii) Egg plants}

The egg plant data are supplied by Gotoh (1953) and consist of a 5 by 5 diallel scored for a variety of characters. These observations have been previously analysed by Griffing's (1950) extension of Hull's constant parent regression technique.

The analyses of the various characters are given in table 4 .

Using Griffing's analysis, Gotoh found it necessary to transfer the weight of fruit observations to a logarithmic scale but found the linear scale satisfactory for the other characters scored. Re-analysis of these data on the original scale by any of the scaling tests that are applicable to an $F_{1}$ diallel (Jinks and Hayman, I953) shows no justification for rescaling. There is, however, extreme inequality of allele frequencies in the parent lines for weight of fruit and flowering time, i.e. $\mathrm{F}$ is almost as large as $\mathrm{D}$ and $\overline{\mathrm{uv}}$ is much smaller than 0.25 . 
This would necessitate rescaling if Griffing's method of analysis is employed. In fact, Griffing's method is unable to distinguish between disturbances resulting from non-random distribution of alleles in the parental lines and those arising from genic interactions.

Weight of fruit, and shape of fruit, both show significant but incomplete dominance while the regressions of $\mathrm{Wr}$ on $\mathrm{Vr}$ all agree with a slope of $\mathrm{r}$, i.e. there is no suggestion of non-allelic interaction for these characters. Flowering time, on the other hand, shows

TABLE 4

\begin{tabular}{|c|c|c|c|c|}
\hline & $\begin{array}{l}\text { Weight of } \\
\text { fruit }\end{array}$ & $\begin{array}{l}\text { Shape of } \\
\text { fruit index }\end{array}$ & $\begin{array}{l}\text { Flowering } \\
\text { time }\end{array}$ & $\begin{array}{l}\text { Bunchiness of } \\
\text { fruit }\end{array}$ \\
\hline $\begin{array}{l}\mathrm{D} \cdot \\
\mathrm{F} \\
\mathrm{H}_{1}: \\
\mathrm{H}_{2} \cdot \\
\frac{\mathrm{H}_{1}}{\mathrm{D}} \cdot \\
\overline{\mathrm{uv}} \cdot \\
\mathrm{b}_{\mathrm{Wr}} / \mathrm{vr} \\
\frac{1}{\mathrm{~d}\left(\mathrm{D}-\mathrm{H}_{1}\right)}\end{array}$ & $\begin{array}{c}24,460 \cdot 70 \\
-21,260 \cdot 16 \\
12,058 \cdot 58 \\
7,412 \cdot 13 \\
0 \cdot 493 \\
0 \cdot 155 \\
1 \cdot 029 \pm 0 \cdot 026 \\
3,100 \cdot 53 \pm 502 \cdot 67 \\
\left(D>\mathrm{H}_{1}\right)\end{array}$ & $\begin{array}{c}6 \cdot 064 \\
-0.565 \\
0.939 \\
0.767 \\
o \cdot 155 \\
0.204 \\
\mathrm{I} \cdot 010 \pm 0.036 \\
\mathrm{I} \cdot 28 \mathrm{I} \pm 0 \cdot 010 \\
\left(\mathrm{D}>\mathrm{H}_{1}\right)\end{array}$ & $\begin{array}{c}31 \cdot 5 \mathrm{I} \\
+18.6 \mathrm{I} \\
20 \cdot 02 \\
4.55 \\
0.635 \\
0.057 \\
0.855 \pm 0.228 \\
2 \cdot 873 \pm 2 \cdot 25^{\circ} \\
\left(\mathrm{D}=\mathrm{H}_{1}\right)\end{array}$ & $\begin{array}{c}\mathrm{r} \cdot 9 \mathrm{r} 4 \\
+0 \cdot 326 \\
0 \cdot 080 \\
\ldots \\
o \cdot 042 \\
\ldots \\
\ldots \\
\ldots\end{array}$ \\
\hline
\end{tabular}

complete dominance, but again gives no suggestion of non-allelic interaction.

The other character scored, bunchiness of fruit, consisted of only one array, i.e. one parental line crossed to four others. The appropriate formulæ for this type of analysis are as follows :

$$
\begin{aligned}
& \mathrm{V}_{\text {OLO }}=\mathrm{D} \\
& \mathrm{V}_{\mathrm{r}}=\frac{1}{4} \mathrm{D}+\frac{1}{4} \mathrm{H}_{1}+\frac{1}{4} \mathrm{~F}_{\mathrm{r}} \text { where } \mathrm{F}_{\mathrm{r}}=\Sigma 8 \mathrm{uvdh} \\
& \mathrm{W}_{\mathrm{r}}=\frac{1}{2} \mathrm{D}+\frac{1}{4} \mathrm{~F}_{\mathrm{r}}
\end{aligned}
$$

\begin{tabular}{|c|c|c|c|c|}
\hline & & Yield & Height & $\begin{array}{l}\text { Sowing to } \\
\text { harvesting }\end{array}$ \\
\hline $\begin{array}{l}\mathrm{D} \\
\mathrm{H}_{1}: \\
\mathrm{F} \\
\frac{\mathrm{H}_{1}}{\mathrm{D}} \cdot\end{array}$ & $\begin{array}{l}\cdot \\
\cdot \\
\cdot\end{array}$ & $\begin{array}{r}60,635 \cdot 61 \\
554,104 \cdot 99 \\
+148,862 \cdot 50 \\
9 \cdot 13^{8}\end{array}$ & $\begin{array}{r}74 \cdot 33 \\
232 \cdot 40 \\
+128 \cdot 69 \\
3 \cdot 126\end{array}$ & $\begin{array}{r}1 \cdot 314 \\
1 \cdot 237 \\
-0.500 \\
0.942\end{array}$ \\
\hline
\end{tabular}

This analysis gives no estimate of $\mathrm{H}_{2}$ and hence of $\overline{\mathrm{uv}}$, nor a test of non-allelic interaction when confined to $F_{1}$ data only. It does permit one to estimate the degree of dominance without, however, providing a test of significance from the regression of $\mathrm{Wr}$ on $\mathrm{Vr}$. In this particular case dominance is negligible (table 4).

One further set of crosses has been analysed consisting of a single array, i.e. $\mathrm{I} \times 9$ crosses. This gives no information about the incidence of non-allelic interaction, but it is of interest in so far as it contrasts 
with the other results in showing overdominance, spurious or otherwise, for some of the characters scored. These data are given in a paper by Kakisaki (I93I) and include observations on yield, final height and the period from sowing to harvesting. The analyses are set out in table 5 .

\section{(iii) Galeopsis}

It is possible to extract some complete diallel tables from the results of numerous crosses made by Hagberg (1952a, 1952b) within

TABLE 6

\begin{tabular}{|c|c|c|c|c|}
\hline & 1947 & $194^{8}$ & 1950 & $\begin{array}{c}\text { G. bifida } \times \\
\text { tetrahit, } 1947\end{array}$ \\
\hline $\begin{array}{l}\mathrm{D} \\
\mathrm{H}_{1}: \\
\mathrm{H}_{2} \cdot \\
\mathrm{F}^{\prime} \cdot \\
\frac{\mathrm{H}_{1}}{\overline{\mathrm{D}}} \cdot \\
\overline{\mathrm{uv}} \cdot \\
\mathrm{b}_{\overline{\mathrm{Vr}}}^{\mathrm{Wr}} \cdot \\
t\left(\mathrm{D}-\mathrm{H}_{1}\right) .\end{array}$ & $\begin{array}{c}138.917 \\
19.750 \\
13.521 \\
+6.916 \\
0.14^{2} \\
0.171 \\
0.910 \pm 0.018 \\
29.79 \pm 0.60 \\
\left(D>H_{1}\right)\end{array}$ & $\begin{array}{c}170.917 \\
41.333 \\
29.93^{8} \\
+10.75^{0} \\
0.24^{2} \\
0.181 \\
0.926 \pm 0.030 \\
32.39 \pm 2.43 \\
\left(\mathrm{D}>\mathrm{H}_{1}\right)\end{array}$ & $\begin{array}{c}251 \cdot 300 \\
29 \cdot 660 \\
25 \cdot 120 \\
-53 \cdot 200 \\
0 \cdot 118 \\
0.212 \\
1 \cdot 079 \pm 0 \cdot 113 \\
55 \cdot 41 \pm 2 \cdot 28 \\
\left(\mathrm{D}>\mathrm{H}_{1}\right)\end{array}$ & $\begin{array}{c}95 \cdot 000 \\
11 \cdot 500 \\
9 \cdot 083 \\
-10 \cdot 667 \\
0 \cdot 121 \\
0 \cdot 198 \\
0.939 \pm 0 \cdot 167 \\
20 \cdot 88 \pm 1 \cdot 10 \\
\left(D>H_{1}\right)\end{array}$ \\
\hline
\end{tabular}

and between varieties of Galeopsis tetrahit and bifida carried out over a number of seasons. The largest of these tables for flowering time is provided by a 5 by $5 \mathrm{~F}_{1}$ diallel within varieties of $G$. tetrahit. Two further 4 by 4 diallel sets of crosses involving the same parental lines can be extracted from the 1947 and $194^{8}$ data which have three parents in common with the I950 diallel. The analyses are given in table 6 .

TABLE 7

\begin{tabular}{|c|c|c|c|c|}
\hline & & Single array & $3 \times 3$ diallels I & II \\
\hline $\begin{array}{l}\mathrm{D} \cdot \\
\mathrm{H}_{1}: \\
\mathrm{H}_{2}: \\
\mathrm{F} \\
\mathrm{H}_{1} \cdot \\
\overline{\mathrm{D}} \cdot \\
\overline{\mathrm{uv}} \cdot \\
\mathrm{b} \mathrm{Wr} / \mathrm{Vr} \\
\mathrm{L}\left(\mathrm{D}-\mathrm{H}_{1}\right)\end{array}$ & : & $\begin{array}{c}34 \cdot 629 \\
58 \cdot 334 \\
\ldots \\
-57 \cdot 016 \\
1 \cdot 685 \\
\ldots \\
\ldots \\
\ldots\end{array}$ & $\begin{array}{c}43.333 \\
281.891 \\
201 \cdot 216 \\
+92.216 \\
6.505 \\
0 \cdot 179 \\
0.993 \pm 0.375 \\
-59 \cdot 65 \pm 5.52 \\
\left(\mathrm{D}<\mathrm{H}_{1}\right)\end{array}$ & $\begin{array}{c}19 \cdot 000 \\
12.556 \\
11 \cdot 112 \\
+1 \cdot 333 \\
0.608 \\
\\
0.221 \\
0.953 \pm 0.206 \\
1 \cdot 61 \pm 0.58 \\
\left(\mathrm{D}=\mathrm{H}_{1}\right)\end{array}$ \\
\hline
\end{tabular}

Over all years there is significant but incomplete dominance, with no suggestion of non-allelic interaction.

It is impossible to extract diallels larger than 3 by 3 from the height data. It is possible, however, to extract a single array $(\mathrm{I} \times \mathrm{II})$ and two 3 by 3 diallels chosen from amongst these 12 parents. The analyses are given in table 7 . 
The analysis of the single array shows slight overdominance which unfortunately cannot be tested for significance since none of the tests is applicable. Of the selection of two 3 by 3 diallels from amongst the parents making up the single array, one shows significantly high overdominance while the other shows no significant deviation from complete dominance. There is, however, only one degree of freedom for testing the $\mathrm{WrVr}$ regression for non-allelic interaction and neither regression is significant. Although a high intensity of non-allelic interactions can give rise to a non-significant regression, we cannot with any confidence ascribe it to this cause in the present case because of the paucity of the material.

The only remaining diallel is a 4 by 4 set of crosses grown in 1947, using two varieties of $G$. tetrahit and two of $G$. bifida as parents. The analysis of the times of flowering show significant but incomplete

TABLE 8

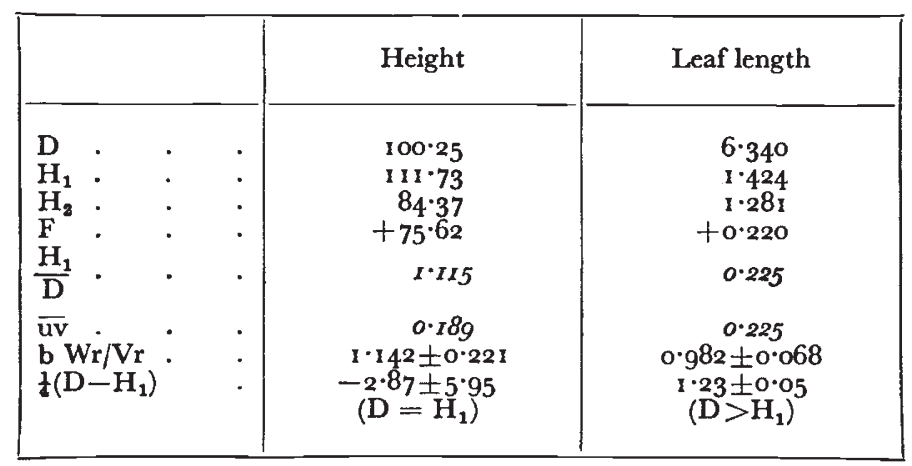

dominance, while the WrVr regression does not differ significantly from a slope of I (table 6). Once again we have neither overdominance nor non-allelic interaction.

\section{(iv) Nicotiona rustica}

Apart from the results which have already appeared on diallel crosses within this species (Jinks, I954b) a 4 by 4 diallel carried out by H. H. Smith (1952) is presented in a form amenable to further analysis.

Amongst the characters scored are height and leaf length, which have added interest in that they are two of the characters used in our own diallel. The analyses are given in table 8 .

For height we find there is complete dominance and no suggestion of non-allelic interaction. Although we found overdominance and significant non-allelic interaction in our own data it will be recalled that only complete dominance remained after omitting the crosses showing non-allelic interaction.

The absence of non-allelic interaction is confirmed for one cross of the diallel set by a joint $\mathrm{F}_{2}$ and backcross scaling test carried out 
by Smith, which revealed no deviation from simple additivity of gene action. Furthermore, all possible double crosses could be predicted with a high degree of precision by Jenkins' method (1940) so that there could be no marked non-allelic interactions between the genes.

The situation found here for leaf length is also similar to our own results, viz. incomplete but significant dominance with no non-allelic interaction.

\section{(v) Flax}

Carnahan (1947) has reported data on flax yields that involve a common variant on the diallel cross technique. It consists of crossing a collection of new varieties with a collection of tester stocks. Thus, instead of giving a diallel table with $\mathrm{n}^{2}$ observations we have a comparable table containing $n_{1} n_{2}$ observations where $n_{1}$ and $n_{2}$ are the number of tester and new varieties respectively.

In the absence of reciprocal differences the statistics obtained from the analysis of rows and columns of a diallel table are estimates of the same thing. In the tester cross type of table, however, the analysis of rows and columns give different estimates depending on the distribution of alleles in the $n_{1}$ and $n_{2}$ sets of parental lines.

If the distribution of the two alleles $A$ and $a$ in the $\mathrm{n}_{1}$ lines is $u$ and $v$ while in the $\mathrm{n}_{2}$ lines it is $s$ and $t$ respectively, we can by analogy with the diallel analysis obtain the following expectations for the statistics :

\begin{tabular}{|c|c|c|}
\hline Statistics & $\mathrm{n}_{1}$ parents & $\mathrm{n}_{2}$ parents \\
\hline $\mathrm{v}_{\mathrm{OLO}}$ & $\Sigma_{4 u v d^{2}}$ & $\Sigma_{4} s t d^{2}$ \\
\hline$V_{x L x}$ & $\Sigma u v d^{2}+u v h^{2}-2 u v \overline{s-t} d h$ & $\sum s t d^{2}+s t h^{2}-2 s t \overline{u-v} d h$ \\
\hline $\mathrm{W}_{\text {OLOr }}$ & $\Sigma 2 u v d^{2}-2 u v \overline{-t} d h$ & $\Sigma_{2} s t d^{3}-2 s t \overline{-v} d h$ \\
\hline $\mathrm{V}_{\text {LOr }}$ & $\begin{array}{l}\Sigma u v d^{2}+u v h^{2}-4 u v s t h^{2} \\
\quad+2 s t u-v d h-2 u t+v s . \overline{u s-t v} d h\end{array}$ & $\begin{array}{l}\Sigma s t d^{2}+s t h^{2}-4 u v s t h^{2} \\
\quad+2 u v s-t d h-2 \overline{u t+v s} . \overline{u s-t v} d h\end{array}$ \\
\hline
\end{tabular}

From these statistics we can estimate $\mathrm{D}, \mathrm{H}_{1}$ and $\mathrm{F}$ defined as follows :

\begin{tabular}{|c|c|c|c|}
\hline & Parameter & $\mathrm{n}_{1}$ parents & $\mathrm{n}_{2}$ parents \\
\hline D & . & $4 \Sigma u v d^{2}$ & ${ }_{4} \Sigma s t d^{2}$ \\
\hline $\mathrm{H}_{1}$ & . & $4^{\Sigma} \Sigma w h^{2}$ & $4 \Sigma s t h^{2}$ \\
\hline F & . & $8 \Sigma u v \overline{s-t} d h$ & $8 \Sigma s t u-v d h$ \\
\hline
\end{tabular}

The estimates of these parameters are given in table 9 . 
The two estimates of the degree of dominance differ as a result of the different weights of the $d$ 's and $h$ 's arising from dissimilar distributions of alleles in the two sets of parental lines. They agree, however, in showing overdominance. The test for non-allelic interaction, which is the same as in the diallel cross, gives no significant regression in both cases.

Only two genetical causes can give rise to a non-significant regression; absence of dominance and non-allelic interaction (fig. I). The first is belied by the high degree of dominance obtained from the $\frac{H_{1}}{D}$ ratios. Furthermore, there is significant heterogeneity among the variances of arrays on Stevens' test (1936) which is incompatible with no dominance (Jinks, I954b). We can only conclude, therefore, that the disturbances in the regression analyses are the direct result of non-allelic interaction. Evidence in favour of this view is supplied by re-analysis of three arrays which deviated least from the best fitting regression line of unit slope. Two of these are from the $n_{2}$

TABLE 9

\begin{tabular}{|c|c|c|}
\hline & $\mathrm{n}_{1}$ parents & $\begin{array}{c}\mathrm{n}_{\mathbf{2}} \text { parents } \\
\text { (tester stocks) }\end{array}$ \\
\hline $\begin{array}{l}\mathrm{D}: \\
\mathrm{H}_{1}: \\
\mathrm{F}^{\prime}: \\
\mathrm{H}_{1} \\
\mathrm{D} \\
\mathrm{b} \text { Wr/Vr }\end{array}$ & $\begin{array}{r}6 \cdot 917 \\
22 \cdot 084 \\
+7 \cdot 167 \\
3 \cdot 193 \\
0 \cdot 288 \pm 0 \cdot 154\end{array}$ & $\begin{array}{c}3.333 \\
46.500 \\
-2.334 \\
13.950 \\
0.087 \pm 0.035\end{array}$ \\
\hline
\end{tabular}

parents and the other from the $\mathrm{n}_{1}$ group. These gave dominance ratios of $\frac{\mathrm{H}_{1}}{\mathrm{D}}=\mathrm{I} \cdot 800$ and $\mathrm{I} \cdot \mathrm{oI} 9$ respectively, which represent a 43.5 and 92.8 per cent. drop in dominance over the inclusive analysis (table 9). This is more than suggestive that non-allelic interaction is again implicated in the high degree of "overdominance".

\section{DISCUSSION}

The first and most important fact that emerges from these analyses is that in no cases have we found evidence of overdominance without also finding evidence for the simultaneous presence of non-allelic interaction. Where it has been possible to test for the presence of interactions in more advanced generations by means of scaling tests they have without fail confirmed our earlier findings.

It has not been possible in all cases to pursue the coincidence of overdominance and non-allelic interaction further than their detection, mainly because of the paucity of the material where the diallel involves small numbers of parental lines. 
In the one case where a complete analysis has been possible, namely our own diallel crosses in $\mathcal{N}$. rustica, the removal of all crosses showing significant non-allelic interaction as detected by the $\mathrm{WrVr}$ regressions and joint $F_{2}$ and backcross scaling tests led to a fall in the dominance ratio to a value of $\frac{H_{1}}{D}=I$. Thus the overdominance can be related to a spurious inflation, in material showing only complete dominance, as a result of non-allelic interaction. The less complete analysis of maize (Kinman and Sprague's data) also showed a fall in the dominance ratio (in this case a 70 per cent. drop) after omitting all crosses from the analysis showing non-allelic interaction on the $\mathrm{WrVr}$ regression and the $\mathrm{F}_{2}$ scaling test, although in this case significant overdominance, at a much lower level, still. remained, as did some evidence of interaction. For the rest of the data we cannot make such sweeping claims with the same degree of confidence because of the necessarily incomplete nature of some of the analyses. But we can with some confidence ascribe the phenomenon described as special combining ability to the direct outcome of non-allelic interaction, while general combining ability can be related to the expression of dominance.

Whether true overdominance, in the sense used by East (1936) and Hull (1945) is operative in any of the data is not made clear from the analyses described here. We can say that in no case is this the sole explanation. We can further say, with some confidence, that it plays no part in any of the $\mathcal{N}$. rustica data so far analysed, while its contribution to the total heterosis in the maize data, at the most can only be of the same order as that of non-allelic interaction and is probably much less. And it is the heterosis produced by the latter, i.e. specific combining ability, that is of primary importance to the maize breeder of to-day. Until such time as observations on segregating generations are available for analysis in the way described by Mather (1949) and Mather and Vines (1952), which would reveal the role of association and linkage in the creation of spurious overdominance, can we hope to be in a position to evaluate the role of true overdominance.

Two further breakdowns of these results are possible, the first relating to the breeding systems and the second to the type of character whose inheritance is under investigation (table ro).

As we pass from outbreeders to inbreeders there is no marked falling off either in the degree of dominance or in the incidence of non-allelic interaction. Moving down the table, however, there is a marked falling off of both. Any attempt to explain this observation must take into account past selection of the character under consideration. Our main problem here is to try and relate the two.

Flowering time, which exhibits neither high dominance nor nonallelic interaction in any of the data analysed, is obviously restricted in its variation as a consequence of its close correlation with time of 
season. That is to say, the extremes of environment within which flowering and hence seed maturation may be brought to a successful conclusion is very limited. Within such a restraint, heterosis of the magnitude met with in characters included under the general heading of vigour would be disastrous for the plant exhibiting it as one or other of the processes leading from flowering to seed maturation would be jeopardised by the prevailing environmental conditions. The genetic system would be further reinforced by the existence of linkage between genes controlling characters such as flowering time as found, for example, in $\mathcal{N}$. rustica (Mather and Vines, I952; Jinks, unpublished).

TABLE Io

Breeding system

\begin{tabular}{|c|c|c|c|c|c|c|}
\hline \multirow{2}{*}{\multicolumn{2}{|c|}{ Character }} & \multicolumn{3}{|c|}{ Outbreeder } & \multicolumn{2}{|c|}{ Inbreeder } \\
\hline & & \multirow{2}{*}{$\begin{array}{c}\text { Maize } \\
8-40\end{array}$} & \multirow{2}{*}{$\begin{array}{c}\text { N. rustica } \\
\ldots\end{array}$} & \multirow{2}{*}{$\begin{array}{c}\text { Egg plants } \\
- \\
0 \cdot 5-9\end{array}$} & \multirow{2}{*}{$\begin{array}{r}\text { Flax } \\
3-14\end{array}$} & $\begin{array}{l}\text { Galeopsis } \\
\text { spp. }\end{array}$ \\
\hline & Dominance & & & & & $\ldots$ \\
\hline YIELD & $\begin{array}{l}\text { NON-ALLELIC } \\
\text { INTERACTION }\end{array}$ & + & $\ldots$ & - or + & + & $\ldots$ \\
\hline & $\begin{array}{l}\text { Dominance } \\
\text { ratio }\end{array}$ & $\ldots$ & $I * 4$ & 3 & $\ldots$ & $0 \cdot 6-7$ \\
\hline Height & $\begin{array}{l}\text { NON-ALLELIC } \\
\text { INTERACTION }\end{array}$ & $\ldots$ & + and - & - or + & $\ldots$ & + and - \\
\hline LEAF & $\begin{array}{c}\text { Dominance } \\
\text { ratio }\end{array}$ & $\ldots$ & $0 \cdot 2-0 \cdot 6$ & $\ldots$ & ... & $\ldots$ \\
\hline CHARACTERS & $\begin{array}{l}\text { NON-ALLELIC } \\
\text { INTERACTION }\end{array}$ & $\ldots$ & + and - & $\ldots$ & $\cdots$ & $\ldots$ \\
\hline FrUit & $\begin{array}{c}\text { Dominance } \\
\text { ratio }\end{array}$ & $\ldots$ & $\cdots$ & 0.2 & $\ldots$ & $\ldots$ \\
\hline SHAPE & $\begin{array}{l}\text { NON-ALLELIC } \\
\text { INTERACTION }\end{array}$ & $\ldots$ & ... & - & $\ldots$ & $\ldots$ \\
\hline FLOWERING & $\begin{array}{c}\text { Dominance } \\
\text { ratio }\end{array}$ & $\ldots$ & 0.5 & $0 \cdot 6-0 \cdot 9$ & $\ldots$ & 0.2 \\
\hline TIME & $\begin{array}{l}\text { NON-ALLELIC } \\
\text { INTERACTION }\end{array}$ & $\cdots$ & - & - & $\cdots$ & - \\
\hline
\end{tabular}

In fact the existence of such phenomena as photoperiodism suggests that there may well be a tying together of genes controlling characters subject to such restraints into supergenes behaving as single switches in response to the right environment. Low dominance, absence of non-allelic interaction and correlated inheritance through linkage would all work towards one end, namely the production of progeny whose flowering behaviour is similar to its own successful parents. This could go a long way towards explaining the observations in table 1o, but we must reserve final judgment until such time as character analyses over all breeding systems are available in order to avoid possible confounding between the two.

When we turn to shape indices, characterised as ratios of lengths 
to breadths, etc. we meet with restraints, which while different in origin will nevertheless have similar effects. In this case heteroses of the magnitude met with in vigour characters would result in a non-functional or mechanically unstable organ.

Undoubtedly, physical and physiological restraints of some type limit the range of expression of every type of character. In some, however, notably the two discussed above, the limits are at once more apparent and more finely balanced. While under strong selection most types of restraint can be broken, except insofar as pleiotropy is operative, they are unlikely to exist in this form in wild populations or unselected material. But it is in vigour characters, where restraints are expected to be less rigid, more than in any of the others, that artificial selection has been sufficiently intense to break down any restraints existing in the wild because of their immediate economic importance.

\section{SUMMARY}

Published data of a number of diallel crosses and related crossing programmes employing such varied material as maize, flax, egg plants, Galeopsis spp. and Nicotiana rustica have been analysed by a method which can discriminate between heterosis arising from interaction between alleles at one locus, i.e. overdominance and that arising from interaction between non-allelic genes. These analyses show that :

(i) Wherever we find overdominance we also find non-allelic interaction.

(ii) Re-analysis of the data after omitting all crosses showing significant non-allelic interaction leads in all cases to a drop in the apparent degree of overdominance and in one case to the complete disappearance of the spurious overdominance.

(iii) Specific combining ability is always associated with the presence of non-allelic interaction while general combining ability is the outcome of uncomplicated dominance.

Acknowledgments.-I am indebted to Professor K. Mather and Dr E. L. Breese for helpful discussion throughout the course of the work described in this paper.

\section{REFERENCES}

CARnahan, H. L. 1947. Combining ability in flax. M.S. Thesis, Univ. of Minnesota. CAVALLI, L. L. I953. An analysis of linkage in quantitative inheritance. Quantitative Inheritance. H.M.S.O. London, pp. I 35-144.

EAST, E. M. 1936. Heterosis. Genetics, 21, 375-397.

EAST, E. M., AND HAYES, H. K. 1912. Heterozygosis in evolution and in plant breeding. U.S. Dept. Agric., Bur. Plant Indust. Bull., 243, 58.

EAST, E. M., AND JONES, D. F. 1919. Inbreeding and Outbreeding : their Genetic and Sociological Significance. J. B. Lippincott Co., Philadelphia and London.

FISHER, R. A., IMMER, F. R., AND TEDIN, O. I932. The genetic interpretation of statistics of the third degree in the study of quantitative inheritance. Genetics, 17, $107-124$. 
сотон, к. 1953. Genetic studies on egg plants. Genetica, 26, 445-452.

GRIFFING, B. 1950. Analysis of quantitative gene action by constant parent regression and related techniques. Genetics, 35, 303-321.

hagberg, A. 1952a. Heterosis in $\mathbf{F}_{1}$ combinations in Galeopsis I. Hereditas, 38 , 33-82.

HAGBERG, A. 1952b. Heterosis in $\mathrm{F}_{1}$ combinations in Galeopsis II. Hereditas, $3^{8,221-245 .}$

hayman, B. I. 1954. The theory and analysis of diallel crosses. Genetics, 39, 789-8og.

hull, F. H. 1945. Maize Genetics Cooperation News Letter, 19, 21-27. Dept. Plant Breeding, Cornell Univ., Ithaca, New York.

HULL, F. H. 1946. Regression analysis of corn yield data. Genetics, 3I, 219.

JENKINS, м. T. 1940. The segregation of genes affecting yield of grain in maize. Fourn. Amer. Soc. Agron., 32, 55-63.

JINKs, J. L. I954a. The genetical basis of heterosis. Maize Genetics Cooperation News Letter, 28, 47-50, etc.

JiNks, J. L. 1954 b. The analysis of quantitative inheritance in a diallel cross of Nicotiana rustica varieties. Genetics, 39, 767-788.

JINKs, J. L., AND hayman, B. I. 1953. Analysis of diallel crosses. Maize Genetics Cooperation News Letter, 27, 48-54, etc.

JONES, D. F. 1917. Dominance of linked factors as a means of accounting for heterosis. Genetics, 2, 466-479.

KAKISAKI, Y. I931. Hybrid vigour in egg plants. Genetics, 16, 1-25.

KINMAN, M. L., AND SPRAGUE, G. F. 1945. Relation between number of parental lines and theoretical performance of synthetic varieties of corn. Fourn. Amer. Soc. Agron., 37, 34 I-35I.

Mather, K. 1949. Biometrical Genetics. Methuen \& Co., London.

MATHER, K., AND VINES, A. 1952. The inheritance of height and flowering time in a cross of Nicotiana rustica. Quantitative Inheritance. H.M.S.O. London, pp. $49-79$.

NILSSON-LEISSNER, G. 1927. Relation of Selfed Strains of corn to $F_{1}$ crosses between them. Fourn. Amer. Soc. Agron., 19, 440-454.

SINGH, R. 1953. Inheritance in maize of reaction to the European corn borer. Ind. Fourn. of Gen. and Plant Breeding, 13, 18-47.

sHull, G. H. 1948. What is " heterosis"? Genetics, 33, 439-446.

SмIтн, H. H. 1952. Fixing transgressive vigour in Nicotiana rustica. Heterosis, pp. I6I-I 74. Iowa State College Press, Ames.

stevens, F. 1936. The physiological consequences of polyploidy. Fourn. of Gen., $33,365-382$. 